\title{
The Global Trends of WSIS: A Case Study of UK’s Plans and Measures on Information Society
}

Elham Abedini*

Division of Social Sciences, University of Tehran, Amir Abad, Iran

*Corresponding author: Abedini E, Division of Social Sciences, University of Tehran, Amir Abad, Iran, Tel: +982161113411; E-mail: elham.abedini@ut.ac.ir

Received date: September 06, 2016; Accepted date: September 26, 2016; Published date: September 30, 2016

Copyright: ( 2016 Abedini E. This is an open-access article distributed under the terms of the Creative Commons Attribution License, which permits unrestricted use, distribution, and reproduction in any medium, provided the original author and source are credited.

\begin{abstract}
The world experienced great scientific and technological changes at the end of the 20th century. Since the importance of information, many scientists presented Information Society related theories. By developing ICTs and increasing importance of information World Summit on Information Society (WSIS, a pair of United Nationssponsored conferences about Information and communication, held in Geneva in 2003. The present study aims to study history of Information Society, WSIS and United Kingdom measures regarding on Information Society and WSIS agendas. Also the researcher considers future priorities of the UK in the field of Information Society.
\end{abstract}

Keywords: Information society; WSIS (World Summit on Information Society); United Kingdom; United Nations; UNESCO; Communication; Regional studies

\section{Introduction}

The world experienced great scientific and technological changes at the end of the 20th century. Mass media and the information and communication technology (ICTs) affect all aspect of society including politics, economy and culture. Declaration of Principles, Building the Information Society: a global challenge in the new Millennium, although many researchers and scientist have referred to the term information society, although there is no agreement on it [1-3].

As it is said in today's society, the quality of life, as well as the prospects for social change and economic development depend increasingly upon information and its exploitation. In such a society, standards of living and advances in information and knowledge influence the patterns of work and leisure, the education system and the marketplace markedly. This is evidenced by an increasing array of information-intensive products and services, communicated through a wide range of media, many of them [4]. The aim of the information society is to act as a source to gain international competitive advantages through using information technology (IT) in a creative and productive way. The importance of the information society and its effects on people's lives led to the organization of The World Summit on the Information Society (WSIS) $[5,6]$.

WSIS is a pair of the United Nations-sponsored conferences on information and communication. On December 21, 2001, the United Nations General Assembly approved Resolution 56/183, endorsing the holding of the first World Summit on the Information Society (WSIS) to discuss information society opportunities and challenges [7].

\section{Statement of the problem}

At the international level, WSIS was held in 2003 in Geneva and in 2005 in Tunis. Some 175 countries participated at the Geneva meeting, and the number of participants at the Tunis meeting was 174 . Participation of the heads of states in these meeting is a proof of the importance of the information society in the future [8]. It appears that the world cannot reach the Information Society in absence of cooperation with other nations. International cooperation is necessary for setting strategic plans. Britain was one of the nations which participated in the both WSIS meetings, and like other parties, signed the documents of Geneva and Tunis meetings $[9,10]$.

The latest meeting in this regard was held under the title of WSIS +10 in the UN General Assembly (15-16 of December 2015) to decide on all documents. Knowing about Britain's plans helps us better understand the United Kingdom's priorities in the Information Society and many other aspects such as education, media, access to information and knowledge, etc. $[11,12]$.

This research aims to show the UK measures and plans concerning WSIS process. This thesis assesses the involvement of the United Kingdom in the World Summit on the Information Society (WSIS) by addressing the dynamics between participation and power. Every plan submitted by countries to the WSIS reflects those countries' policy on specific issues, and collecting information about their plans helps us analyze the situation better.

\section{Research significance}

In today's world, information is power and thus, understanding the term of the information society is necessary in the information era. Furthermore, preparation and maintaining national interests are necessary.

All delegations who participated in the WSIS have plans and strategies to get to the information society. Studying plans of each country is truly helpful to read the future of the world and get ready for it [13]. Likewise, we can apply their experiences and thoughts to be implemented in Iran. As we said before, "information is a tool of power, and we can utilize other countries" experiences as very significant and useful information.

\section{Literature Review}

There is no agreement about the root of "information society" term. Only there are 2 main and popular ideas about it that the information 
society is coming from the United States to Japan. Some believe that at the first time American Economist Fritz Machlup mention information society as "knowledge industry" in the book named "The production and distribution of knowledge" in 1962. In this regard, Cawkell have another idea which is Edwin Parker and Mark Porausesse information society in the article presented in Organization on for economic cooperation and development (OECD) 1975.

Also in Iran we have some scholars and communication professor that works on this field. Some of them are member of Iran delegation in WSIS as Dr. Younes Shokrkhah. The pioneer face of information society in Iran in Dr. Kazem Motamednejad that believes information society alternate postindustrial society and this is the only in the new society. On 1980s, Third Wave, The Information Society as PostIndustrial Society and The Information Economy were published.

William Martion on 1988 defined the Information Society as “...a society in which quality of life, as well as prospects for social change and economic development, depend increasingly upon information and its exploitation. In such a society, living standards, pattern of works and leisure, the education system and the market place are influenced markedly by advanced in information and knowledge".

Ian Milles, another researcher in this field studied on information effects on economy. He examined the empirical evidence suggesting the growing economic significance of information in the economy, concluding that movement toward The Information Society was associated with very diverse tertiary (services) sectors of the economy and, therefore, that analysis must be equally diverse as The Information Society was a 'moving target'.

On the other hand, UNESCO used knowledge society instead of the information society. UNESCO try to promote the concept of knowledge societies rather than that of global information society since enhancing information flows alone is not sufficient to grasp the opportunities for development that is offered by knowledge. Therefore, a more complex, holistic and comprehensive vision and a clearly developmental perspective are needed [14].

Microsoft Chairman Bill Gates stressed the need for governments to embrace technology and outlined the company's commitments to helping government officials become and remain effective leaders in the information age.

Herbert Shiller believes that beyond of the information super highway is company's interests. He said in one interview in that "As the NII (national information infrastructure) policy is being formed and implemented, the interests of the general public are being marginalized. It is not for the public's sake, but for the interest of this much smaller group of influential companies that all of this discussion, all of these programs, and all of this policymaking are moving ahead".

Armand Mattelart acknowledged the opportunities associated with the innovations, but found them to be implemented in ways that replicated the sources of inequality in society [15].

Manuel Castells has highlighted the cultural and institutional manifestations of network societies and the importance or logic of emergent social formations. Castells work is very important for understanding the enabling and disabling characteristics of what he calls 'mass self-communication', that is, the possibilities created by the Internet, including an ever-growing number of social networking sites, and greater access to mobile communication.
European Union has defined information society on its special way. It has a Three-pronged approach to the information society that focuses around.

\section{Three interrelated pillars}

- Stimulating research as a key for future innovation and competitiveness.

- The e-Europe initiative, supporting the development and implementation of Information Society.

- The regulatory framework for electronic communications.

\section{Characters of information society}

Although there are some disagreements on the information society term or its definition but there are some elements that majority of researchers agree with them. We can see the fallowing elements on the most of information society theories.

- Information: Basis of information society that its creation, distribution, use, integration and manipulation have significant effects on economic, political, and cultural activity.

- Information Network: A system containing any combination of computers, computer terminals, printers, audio or visual display devices, or telephones interconnected by telecommunication equipment or cables: used to transmit or receive information.

- Information System: Information System (IS) is a system composed of people and computers that processes or interprets information.

- Information Technology: Is the application of computers and telecommunications equipment to store, retrieve, transmit and manipulate data.

- Information Age Technologies: Wide range of independent technologies that makes information network since they communicate.

- Information Infrastructure: "All of the people, processes, procedures, tools, facilities, and technology which supports the creation, use, transport, storage, and destruction of information".

The notion of information infrastructures, introduced in the 1990s and refined during the following decade, has proven quite fruitful to the Information Systems (IS) field. It changed the perspective from organizations to networks and from systems to infrastructures, allowing for a global and emergent perspective on information systems. Information infrastructure is a technical structure of an organizational form, an analytical perspective or a semantic network. The concept of information infrastructure (II) was introduced in the early 1990s, first as a political initiative by Vice president Al Gore and Geman politician Martin Bangemann, later as a more specific concept in IS research.

\section{WSIS (World Summit on Information Society)}

The World Summit on the Information Society (WSIS) was a couple of United Nations supported meetings about information, communication and, in expansive terms, the information society that occurred in 2003 in Geneva and in 2005 in Tunis.

In 1997, UK government published a report named "Information and Communications Technology in UK Schools" by Lord Dennis Stevenson. After this report, the term ICT (Information and communications technology) became popular. in 1998, the International Telecommunication Union (ITU) taking after a 
proposition by the administration of Tunisia amid ITU Plenipotentiary conference in Minneapolis in 1998, affirmed resolution 73 to hold a World Summit on the information Society and set forward it to the United nations. In 2001, the ITU Gathering chose to hold the Summit in two stages, the first from 10 to 12 December 2003, in Geneva, and the second from 16 to 18 November 2005 in Tunis.

On 21 December 2001, the United Nations General Assembly approved Resolution 56/183 supported the holding of the World Summit on the Information Society (WSIS) to discuss on information society opportunities and difficulties. according to this resolution "The general assembly recognizing the urgent need to harness the potential of knowledge and technology for promoting the goals of the United Nations Millennium Declaration and to find effective and innovative ways to put this potential at the service of development for all".

It calls on governments to actively participate in Summit preparations and to be represented at the highest possible level. It has also asked for the active participation and effective contribution in the Summit and its preparations by all relevant United Nations and intergovernmental organizations, including international and regional institutions, as well as non-governmental organizations, the civil society and the private sector.

\section{Methodology}

The world experienced great scientific and technological changes at the close of the 20th century. Mass media and information and communication technology (ICT) effect on every facet of society includes politics, economics and cultures. Many researchers and scientist called it information society, although there is no accord on this figure.

At the international level, WSIS took place in 2003 in Geneva and in 2005 in Tunis. In Geneva meeting 175 countries and in Tunis meeting 174 countries took part. Participation of head of states in these meeting shows importance of the information society in the future. It seems that the world cannot reach information society without cooperation with other countries. International cooperation is necessary for preparing strategic plans.

Today, information is power and then understanding the term information society is necessary in the information era. The researcher focuses on United Kingdom as a case study to put it in "Network society" as a theoretical framework and answer to some questions.

Main questions that the researcher will try to answer them in this study are:

- What measures were taken by the UK in WSIS (World Summit on Information Society)?

- In which categories of Information Society has United Kingdom been most active in WSIS?

- What are the future priorities of the UK in the field of Information Society?

This chapter presents the research methodology used for this work and how it has guided data collection, analytic thinking and development of theory.

Methodology is the systematic, theoretical analysis of the methods applied to a field of work. It contains the theoretical analysis of the body of methods and principles associated with a branch of knowledge. Typically, it encompasses concepts such as paradigm, theoretical model, phases and quantitative or qualitative techniques.
Qualitative case study research served as the primary methodology for this dissertation. The researcher considers variables include UK plans on information society and also its measures on Europe.

\section{What is case study?}

A case study involves an up-close, in-depth, and detailed examination of a subject (the case), as well as its related contextual conditions. Case studies appear with great frequency throughout popular works, with nearly anybody able to claim to have done one (Encyclopedia of Case Study Research, 2010). Case studies also can be produced by following a formal research method. These case studies are likely to appear in formal research venues, such as journals and professional conferences, rather than popular works. The resulting body of 'case study research' has long had a prominent place in many disciplines and professions, ranging from psychology, anthropology, sociology, and political science to education, clinical science, social work, and administrative science.

\section{Determining the kind of case study}

Since you have found out that the research inquiry is best answered using a qualitative case study and the sheath and its bounds have been decided, then you must consider what type of case study will be conducted.

Yin and Stake use different terms to describe a variety of case studies. Yin categorizes case studies as explanatory, exploratory, or descriptive. He also differentiates between single, holistic case studies and multiple-case studies. Stake identifies case studies as intrinsic, instrumental, or collective. In this article, the researcher will use Qualitative case study methodology in descriptive type.

\section{Findings}

UK played a significant role in WSIS meetings and participates in presenting proposals and also her British delegation had some important lectures at the meetings.

UK Parliament by approving laws and actions, emphasized on, her supporting role and commitment on WSIS action lines. Also, it insisted support EU laws about WSIS.

We support the EU's aims for the World Summit on Information Society (WSIS), which coincide with UK objectives [16].

\section{UK in the WSIS}

UK delegation participated in the all WSIS meetings but the researcher will discuss just about some main UK submitted proposals, reports, speeches and floors in the WSIS meetings.

The main actors of UK in WSIS are The Department of Culture, Media and Sports leads on the WSIS Review, working with the Ministry of Foreign Affairs and others to draft text and coordinate policy positions from the capital using a formalized multistakeholder input process. The UK mission to the UN in New York leads negotiations working with other European Union Member States [17].

\section{UK in Geneva summit, 2003}

In Geneva Summit, UK delegation included 30 persons. Stephen Timms, Minister for E-commerce and Energy was the head of delegation and Mr. Nicholas Thorne, the Permanent Representative of 
the United Kingdom to the United Nations in Geneva, and also to other international organizations in Geneva includes International Telecommunication Union (ITU) and the rest from British NGOs, civil society, private sectors and others participated in the summit [18].

Stephen Timms as representatives of governments in his speech emphasized the most important challenge in the information society is about protecting the more vulnerable citizen from its abuse.

Also he said that international fund to developing countries is not constructive enough and foreign and domestic enterprise and investors should invest in ICT sector.

Timms announced: "The UK Government and many other donors encourage countries to use the development aid we provide to bolster ICT projects. But we do not believe that a new international Fund could tackle the real underlying problems. Nor that it would mobilize even a fraction of the money needed to bridge the digital divide" [19].

\section{UK in Tunisia summit, 2005}

In Tunisia Summit, 33 persons were in UK delegation. This time Alun Michael, minister of state for industry and regions was the head of delegation.in that summit, UK was also the representative on behalf of the European Union and Bulgaria and Romania [20].

He had speech in 16 November and said EU committed to doubling its aid budget by 2010 [21].

Also UK suggested three basic principles for governments to follow:

- To avoid regulation that limits innovation.

- Regulation should deliver market stability and certainty which will attract investment based on open and competitive markets.

- Governments should work in partnership with industry and consumers to find, wherever possible, non-legislative solutions to deal effectively with public policy concerns.

UK delegation on behalf of the European Union tabled a new proposal. It outlined a new framework for international cooperation that would see the creation of a new, multi-stakeholder forum to develop public policy, and most significantly international government involvement in allocation of IP addressing blocks and procedures for changing the root zone file to provide for insertion of new top-level domain names and changes of country-code top level domain name (ccTLDs) managers [22]. The article 29-82 of "Tunis Agenda for the Information Society" is about internet governance.

\section{UK in WSIS forum, 2013}

Department for Culture, Media and Sport, Foreign and Commonwealth Office and BBC was some members of UK delegation in WSIS Forum 2013 [23].

Also Karen Pierce, the Permanent Representative of the United Kingdom to the United Nations in Geneva, and also to other international organizations in Geneva includes International Telecommunication Union(ITU) was participated [24].

United Kingdom had an Intervention from the floor, UK commented that:

- It has been a challenging week and an important week, but we believe that some issues need further dialogue in open settings. For instance, the role of government, capacity building and addressing vital issues like access - especially in developing countries - merit more attention, we look to the WSIS+10 to address those issues;

- WSIS Forum has proved to be a good opportunity to learn and to meet many committed stakeholders. The UK commends Dr Touré and all the staff for their hard work [25].

\section{UK in WSIS+10 high-level events, 2014}

Mark Matthews, ambassador and deputy permanent representative to the United Nations and other International Organizations in Geneva as ITU made a speech in the meeting. He emphasized on close cooperation between the governments and non-government stakeholders. Also he as a UK representative asks to work hard to find a compromise and in particular to agree a balanced approach to Action Line C9 on the media.

He said that: "For us, the principles of freedom of expression, the independence, plurality and diversity of the media and the safety of journalists are fundamental, any text which does not include those principles cannot be said to be balanced" [26].

According to the speech, UK had 3 recommendations [26]:

- We need to consider the impact that ICTs have on the environment and on climate change, minimizing waste and ensuring it is handled responsibly.

- People with disabilities face particular challenges. As we rely on ICTs more and more in our everyday lives, there is a risk that disabled people will become increasingly excluded. We need to harness the benefits of new and innovative technology to help ensure that all members of society are able to benefit.

- In many parts of the world, freedom of expression online is curtailed by censorship or blocking, denying citizens their fundamental rights and undermining transparency and accountability.

\section{UK in WSIS forum, 2015}

Julian Brathwaite, ambassador and permanent representative to the United Nations and other International Organizations in Geneva as ITU made a speech in the meeting.

He emphasize still there are some real and important challenges that world need to address in the future [27]:

- To address the digital divide in broadband provision.

- To mainstream ICTs into broader social and economic agendas.

- To continue to invest in education and capacity building.

It is mentioned that The United Kingdom has some key aims for 2015 review of WSIS by the UN General Assembly [27]:

- To make sure that WSIS is focused on development and on identifying practical steps to support developing countries and to enable people around the globe to harness the huge potential of ICTs for development.

- How the WSIS action lines can align with the post-2015 sustainable agenda.

- To extend the mandate of the internet governance forum for a further ten years. The IGF has demonstrated its worth as an open global platform for all stakeholders.

- To build stronger links between the regional and national IGFs which have developed over recent years to become a truly bottomup global platform? 
- To strengthen an open and inclusive multi-stakeholder model of governance.

\section{UK in 2nd preparatory meeting - for the General Assembly's overall review of the implementation of the outcomes of (WSIS)}

UK in 2nd Preparatory Meeting for the General Assembly's overall review of the implementation of the outcomes of the World summit on the Information Society held in (WSIS) 20-22 October 2015 in United Nations headquarters, New York presented a statement entitled "UK contribution to EU opening statement [28].

UK announced its disagreement with calls for an international legal framework for Internet governance. UK said: We do not support calls for an international legal framework for Internet governance. This would undermine the multi-stakeholder governance model that was agreed at Tunis and put at risk the dynamism and innovation which across the world have brought so many social and economic benefits.

We are also disappointed at the suggestion of a 5 year extension to the mandate of the Internet Governance Forum [28]

\section{Golden Book}

The Golden Book is intended to promote new commitments that stakeholders have announced, or are planning to announce during the Tunis Phase of the WSIS. The intention is to promote these new commitments particularly to the media in a way that will complement those initiatives already underway, as recorded in the WSIS stocktaking database [29].

The Golden Book was launched in October 2005 and has been frozen on the 31st of January 2006.

UK stakeholders submitted two commitments in the Golden Book as follows:

- Soroptimist International (a website based method of linking eligible women to membership of Soroptimist International).

This project aimed to support a number of the objectives set out in the WSIS Geneva Plan of Action 2003: to address the special requirements of persons with disabilities to ensure their full inclusion in the Information Society; to launch pilot projects to design new forms of ICT-based networking; to empower local communities, especially those in rural and underserved areas, in ICT use and promote the production of useful and socially meaningful content for the benefit of all [30].

- Exhibit Choice Ltd (a web site devoted to building ICT's in developing countries): This global initiative emerged from discussions with stakeholders during the African prep-com phase. It was felt that existing information resources focus primarily on the 1st world and that a commercially funded, global reach, information source would offer a valuable contribution to achieving the WSIS goals.

\section{WSIS Action Lines}

First the researcher will UK own actions about information society. For example, the government actions and parliament's laws, then we will study about digital agenda plan that approved by EU and its status in the UK.

\section{C1 - The role of governments and all stakeholders in the promotion of ICTs for development}

UK coalition government said that the information and communications technology (ICT) is critical for the effective operation of government and the delivery of the services it provides to citizens and businesses [31].

The Government published ICT strategy aims building of a common infrastructure underpinned by a set of common standards. It plans decrease costs and increase saves by increasing public sector productivity and efficiency.

\section{UK ICT strategy fall into four part include}

Part 1 - Reducing waste and project failure, and stimulating economic growth

The Government is committed to improving the way it delivers ICT enabled business change so that investments in ICT support business needs and deliver expected benefits. To do this, government will adopt the right methods and policies and develop a skilled workforce in order to improve and exploit its ICT. By reforming its approach to ICT, government will also help to stimulate economic growth by creating a fairer and more competitive marketplace, with greater direct opportunities for small and medium-sized enterprises (SMEs) [31].

\section{Part 2 - Creating a common ICT infrastructure}

To carry out its day-to-day operations, government relies on complex and large-scale ICT infrastructure components. However, government departments have traditionally worked independently to design, procure and run their own ICT solutions. This has resulted in an expensive and fragmented ICT infrastructure which often duplicates solutions and impedes the sharing and reuse of services. A new approach is required to create the ICT that will deliver the modern public services which citizens and businesses expect [31].

As UK government claims, it is important to fallow up different ICT strategies together. UK said that common technology standards will enable the delivery of an open platform to support smaller, interoperable solutions. By opening up access to this platform, government will be able to procure solutions directly from SMEs rather than predominantly via systems integrators, helping to create a fairer and more competitive ICT marketplace [31].

And also UK emphasize that to connect, mobilize and reduce cost across the public sector, the Government will further exploit mobile technologies, collaboration tools, and video and teleconferencing. These technologies will equip the public sector workforce with the tools to operate flexibly, providing additional benefits to customers. Working flexibly will facilitate the rationalization of the public sector's large and diverse property estate, reduce travel costs and carbon footprint, and have a beneficial impact on productivity.

\section{Part 3 - Using ICT to enable and deliver change}

By standardizing processes and creating transparent commercial models, the Government will build a common, flexible ICT infrastructure. This ICT platform will enable the delivery of open, diverse and responsive public services for all [31].

\section{Part 4 - Strengthening governance}

The strategy will be delivered through lead departments accepting responsibility for actions and parts of the ICT infrastructure model 
where delivery activities are already aligned with their work. This form of devolved delivery will require new and robust governance [31].

Also the UK in 2014 published "Information Communications Technology (ICT) in the UK: investment opportunities" guidance.

The UK encourages domestic and overseas companies to invest in ICT sector in the country. It claims that "it is one of the world's largest information communications technology (ICT) markets" [32].

\section{UK government support companies in these fields}

\section{Software development}

The UK develops software for many applications and international companies provide funding for research and development (R\&D). About 100,000 software companies operate in the UK including Microsoft, IBM and HP.

\section{Mobile device market}

The UK's mobile market is the largest in Europe with a value of $£ 14$ billion annually and 80 million mobile subscriptions. This means companies are always looking at new opportunities to use mobile technology and improve the experiences of consumers.

\section{Cloud computing}

The UK cloud computing market is predicted to reach $£ 6.1$ billion by 2014 and offers big investment opportunities for companies in the ICT sector [33].

The main reasons for businesses using cloud services in the UK are:

- Flexibility in meeting business demands

- Quicker disaster recovery

- Automation of software updates

- Increased collaboration between employees

- Reduction of costs

- Low cost of using cloud services

\section{Data centers}

Opportunities exist across the data center supply chain in the public and private sector.

Also UK helps public and private companies to secure and protect data.

\section{Cyber security}

The UK’s cyber security market is worth about $£ 2.8$ billion. Growth in this area is due to increased awareness of cyber threats and the development of more connected services. Mobile phone security is expected to be one of the largest markets over the next few years as more people start using mobile devices for mobile commerce (mcommerce) [34].

\section{Research networks and support}

There are seven main organizations and networks that study about the efficiency of data centers, business computing systems, public sector IT and opportunities as follows:

- British Computer Society Data Centre Specialist Group (DCSG).

- The green grid.

- Datacenter dynamics.

- Energy Services and Technology Association (ESTA).
- Cloud industry forum.

- Tech UK.

- Kable.

\section{Locations}

There are different locations across the UK known as Enterprise Zones that offer investors' incentives to locate themselves there including:

- Reduced taxes.

- Simpler planning rules.

- Financial benefits.

\section{C2-Information and communication infrastructure: an essential foundation for the information society}

HM treasury and Department for Culture, Media \& Sport in UK published a Policy paper called "the digital communications infrastructure strategy" on March 2015. It includes UK government strategy for the future, rising demand for data capacity and supporting the market to deliver better connectivity.

UK strategy about future of information and communication infrastructure is that ultrafast broadband of at least $100 \mathrm{Mbps}$ should become available to nearly all UK premises. On the other hand, UK committed to ensuring that people in rural areas can access high-speed broadband [35].

UK claims that more than $80 \%$ of the UK citizen can access superfast services of at least $24 \mathrm{Mbps}$, with services being made available to 40,000 extra premises every week. Also 4G (4th Generation) is spreading rapidly across the UK. The average price of a broadband package decreased by $48 \%$ between 2004 and 2012 [35].

According to Ofcom (communications regulator in the UK) report, UK has the highest e-commerce spending among major nations, with consumers spending an average of almost $£ 2,000$ online on goods each year [36].

Demand for digital services and applications are continuing to rise rapidly, so the UK needs infrastructure that is high capacity, reliable, resilient, secure, and affordable and fast [35].

According to ITU, 96 percent of rural British population covered by a 3G mobile cellular signal in 2012 [37].

UK in 2014 asks industry, academia, consumers, business organizations and institutes to consult UK about its future strategy in response of increasingly demand of data capacity. In the fallow its tools bring [35].

- Video services: Continual development of the quality and nature of video services with the adoption of $4 \mathrm{k}$ and possibly $8 \mathrm{k}$ services.

- Cloud services, applications and resources: Increased use of large groups of networked, remote servers centralizing data storage and online access to services and resources.

- Education services: Increased use of cloud technology by multiple users demanding business quality connections to fiber network.

- Smart cities: Infrastructure, local skills, community institutions and digital technologies brought together to fuel sustainable, economic development and provide an attractive environment.

- Big data: New methods and tools to use and manipulate vast quantities of data, often in real time. 
- Internet of things machine (M2M) communications: 170-530 million M2M devices connected in the UK by 2022.

- Health services: Increasing reliance on M2M technology and applications providing remote healthcare and working.

- Electricity networks: Smart grids enabling dynamic real time flows of information and interaction between consumers and suppliers and between parts of the supply chain.

On the other hand, the government has taken steps to support small businesses, charities, social enterprises and sole traders through its broadband connection voucher scheme, which provides grants of up to $£ 3000$ to SMEs looking to upgrade their broadband connections [38].

\section{C3-Access to information and knowledge}

The UK Supreme Court adopted laws about freedom of information and data protection policies [39].

About the right to Internet access, the researcher will mention Summary of broadband development in the United Kingdom [40].

All people must be able to access the Internet in order to exercise and enjoy their rights to Freedom of expression and opinion and other fundamental human rights as access to information and knowledge, that states have a responsibility to ensure that Internet access is broadly available, and that states may not unreasonably restrict an individual's access to the Internet $[41,42]$.

The British government's targets for superfast broadband availability set in the national broadband strategy of the United Kingdom is to a large extent consistent with the European Commission's Digital Agenda for Europe (DAE) targets [43,44].

The Government Department for Culture, Media and Sport (DCMS) is responsible for setting the direction of the Broadband Delivery Program. Broadband Delivery UK (BDUK) is part of DCMS and is the delivery vehicle for the Government's policies relating to stimulating private sector investment using available funding across the UK [44].

In 2010, UK adopted "The strategy Britain's Superfast Broadband Future" and updated in 2012 and 2013. It is valid until 2017. To achieve the objectives, a mix of technologies -fixed, wireless and satellite - will be needed to deliver superfast broadband throughout the UK [45].

\section{C4 - Capacity building}

The government aims to make sure that further education provides the skilled workforce employers need and helps individuals reach their full potential [46].

In order to improve the British citizen's skills, it is not enough to focus on initial education and training but also employers should invest in and improve the skill levels of employees, including on-thejob training, in-house development programs and coaching [47].

UK government through different departments implement London policies about improve worker's skills as "UK Commission for Employment and Skills "and "Skills Funding Agency" [48].

\section{C5 - Building confidence and security in the use of ICTs} [49].

UK government claims that cyber security a top priority for her
In November 2015 UK Chancellor pledged to increase spending on cyber security to $£ 1.9$ billion by 2020 , recruit 1,900 new staff across the three intelligence agencies and establish the first National Cyber Centre, which will be home to the country's first dedicated 'cyber force' [49].

\section{C6-Enabling environment}

According to WSIS action lines, C6 means that "Governments should foster a supportive, transparent, pro-competitive and predictable policy, legal and regulatory framework, which provides the appropriate incentives to investment and community development in the Information Society" [50].

UK government implements policies about develop internet usage, faster broadband and ICT applications, details of them is available in other action lines as C1, C2 and C7.

\section{C7- ICT applications: benefits in all aspects of life}

ICT applications supports sustainable development, in the fields of public administration, business, education and training, health, employment, environment, agriculture and science within the framework of national e-strategies. This would include actions within the following sectors [51].

\section{E-government}

UK estimated that moving services from offline to digital channels will save between $£ 1.7$ and $£ 1.8$ billion a year [52].

UK published "The Government Digital Strategy" and redesigns her digital services to make them so straightforward and convenient that all those who can use them prefer to do so.

Improve departmental digital leadership: All departments will undertake end-to-end service redesign of all transactional services with over 100,000 transactions each year.

Develop digital capability throughout the civil service: All departments will ensure that they have the right levels of digital capability in-house, including specialist skills. Cabinet Office will support improved digital capability across departments.

Redesign transactional services to meet a new Digital by Default Service Standard: All departments will undertake end-to-end service redesign of all transactional services with over 100,000 transactions each year.

Complete the transition to GOV.UK: Corporate publishing activities of all 24 ministerial departments moved onto GOV.UK by March 2013.

Increase the number of people who use digital services: Departments will raise awareness of their digital services so more people know about and use them, and look at ways to use incentives to encourage digital adoption.

Provide consistent services for people who have rarely or never been online: It is important that nobody is left behind in this move to a digital by default approach. Departments will recognize and understand the needs of people who can't use digital services. The government will provide appropriate support for these people to use digital services and other ways to access services for people who need them. 
Broaden the range of those tendering to supply digital services including more small and medium sized enterprises: Cabinet Office will offer leaner and more lightweight tendering processes, as close to the best practice in industry as our regulatory requirements allow.

Build common technology platforms for digital by default services: Cabinet Office will lead in the definition and delivery of a new suite of common technology platforms, to underpin the new generation of digital by default services.

Remove unnecessary legislative barriers: Cabinet Office will work with departments to amend legislation that unnecessarily prevents us from developing straightforward, convenient digital services.

Base service decisions on accurate and timely management information: Departments will supply a consistent set of management information, as defined by Cabinet Office, for their transactional services.

Improve the way that the government makes policy and communicates with people: Departments will encourage policy teams to use a wider range of digital tools to communicate with and consult people, both within the UK and overseas.

Collaborate with partners across public, private and voluntary sectors to help more people go online: Departments will build digital inclusion into all relevant policies and programs, and collaborate with private and third sector organizations to remove barriers to internet use, whether caused through lack of skills, motivation, access or trust.

Help third party organizations create new services and better information access for their own users by opening up government data and transactions: Departments will undertake cross-government discovery work with GDS to understand user needs for services delivered outside GOV.UK, and what APIs and open standards might be required to support them; and GDS will undertake development work on GOV.UK to make all information held on it easily reusable.

\section{E-business}

UK claims that by 2018 , the value of her e-commerce is estimated to be $£ 60$ billion (from $£ 10$ billion in 2013) [53].

UK government designed a plan called "e-exporting" to develop ecommerce. It is building relationships with the world's leading online marketplaces, which allow UK companies to list themselves and export their goods to new international markets [54].

Financial Times newspaper published a report in 2012 about UK online shopping. It said that "British shoppers make 13.5 per cent of their purchases online, higher than 7.1 per cent in Germany, 5 per cent in the US and 6.6 per cent in the world's most wired nation, South Korea. Even more customers choose to research online and buy in store" [55].

\section{E-learning}

The UK has a long history of seeking to develop the use of ICT in schools but the launch of the National Grid for Learning in 1997 was different in three crucial respects, these being scale, the integrated approach to infrastructure and human resources and thirdly the political philosophy of the "third way" and marketization which underpins the principles of Connecting the Learning Society which opened the consultation on this initiative [56].
In 2003 launch of the Department for Education and Skills (DFES) eLearning Strategy consultation in England represents an important context for this. Now there many educational institutions and authorities that have developed, or are developing, ICT and e-learning policies which will shape education business decisions and impact directly on educational delivery [57]. The UK Government's commitment to ICT in education is not new. The Government has invested heavily in ICT in schools, including major investment in infrastructure, like computers and connectivity, funding for software via the Curriculum Online program, and ICT training for teachers [58].

Although The Guardian newspaper published a report in 2014 about online learning in UK and claimed it situation is not good enough. It compared US and UK online learning and said it is still seen as the poor relation in the UK - but it's time for attitudes to change [59].

According to UNESCO Institute for Statistics (UIS), more than 95 percent of British teachers trained to teach using ICT versus those teaching using ICT in 2012 [14].

\section{E-health}

UK has important and comprehensive health system names NHS. The NHS Plan had also redefined the various relationships between the health services and the patient.

In 2005 the Department of Health designs its policies about ICT developments to Connecting for Health (CFH) which also assumed the IT responsibilities of the NHS Information Authority (NHSIA) which was subsequently closed [60].

\section{E-employment}

UK government has plans to develop teleworking and also usage of ICT in work offices. "Employment Relations Directorate" in "Department of Trade and Industry".

According to the UK Labor Force Survey, there are 2.2 million teleworkers in the UK - about $7.4 \%$ of the workforce. This is people who work at home at least one day per week [61].

\section{E-environment}

UK government published a special strategy perspective about environment. "Greening government ICT strategy" is a paper policy that publishes annually from 2011 . This sets out how government ICT will contribute to green commitments and deliver financial savings as well as efficient, green practices [62].

UK government establishes a new unit called Green ICT Delivery Unit (GDU). It is focused on developing supporting tools and guidance and then transparently reporting on progress. The GDU also reaches out to the UK ICT industry, through organizations such as Tech UK, JISC (Joint Information Services Committee for Higher Education) and the BCS (British Computer Society), working together to identify opportunities and to push for improvement [63].

UK government slogan in environment policy field is "reduce carbon, reduce cost", so we expect that UK cares about reducing carbon and air pollution [64].

For example, Home office develops its research team to go into more details and data about use energy and amount of carbon productivity. 
In May 2014, Department for energy and climate change moved to a new multi-supplier tower model for the provision of its core IT services. Most of the department's IT is now commodity and cloud based and therefore typically greener by design.

The Department for transport reduces the number of printers in use and improves the service. It reduced the number of printers in service from more than 500 down to 130 and also reduces number of PCs and laptops. It helps to reduce usage of electricity and product of $\mathrm{CO}_{2}$.

The Ministry of Justice plans to power saving by turning off computers in midnight. It set to save more than $£ 217,000$ a year and make a substantial contribution to reducing its carbon emissions by deploying the Night Watchman. The Night Watchman is an innovative piece of software which identifies desktop PCs that have been left on overnight and automatically shuts them down. Any unsaved work is automatically saved so no data is lost.

Department of Business Innovation and Skills increased IT performance and capacity (from $220 \mathrm{~TB}$ to over $1 \mathrm{~PB}$ of disk storage) in National Oceanography Center that reducing its energy usage by about $50 \%$.

Those are just some examples of UK efforts to reduce carbon and air pollution. It has cultural and operational projects to reach the fallowing goal [65].

\section{Using ICT more efficiently - the end users}

Government will make efficiency savings on existing ICT equipment by encouraging behavior changes, such as turning off equipment at night, printing less, reducing email traffic and archiving data as advised by local green policies. Where possible, "dematerialization" of activities; swapping high for low carbon options, should be encouraged. For example: teleconferencing, e-publishing instead of printing.

\section{Using ICT to reduce travel}

Much of government operations involve cross-departmental working; collaborative ICT tools will therefore increase productivity and the efficiency of government. Government will be encouraged to use collaboration tools, allowing staff to view and edit the same documents when they are not in the same location. The Government will use ICT to reduce the need for travel by deploying and actively promoting use of audio, video and web conferencing facilities.

\section{Using ICT to reduce consumables}

Advances in technology make it easier to use electronic documents without printing them. These reduce running costs and environmental impacts. Government will reduce its paper printing requirements by providing electronic methods of working, such as collaborative tools which can minimize the need for multiple copies, attendant printing and paper consumption. Electronic archiving of documents needs less space than paper ones, reducing the size of the government estate.

\section{Using ICT to streamline business operations}

Government is examining many of its end to end business processes and will exploit ICT where appropriate to cut unnecessary steps, data retention or transfer. This will reduce cost, greenhouse gas emissions, waste, paper, and travel and office space, maximizing contributions to the Greening Government Commitments.

Exploiting ICT to work smarter
Flexible and remote working can decrease travel costs, downtime and enable office space rationalization to occur. These offer the potential for efficiency savings, by reducing estate running costs and environmental impacts. These forms of smarter working and the more agile office spaces that accompany them are only enabled by appropriate ICT i.e., collaboration tools, the cloud, unified communications and other remote access technologies.

\section{Drive behavior and change}

To achieve these efficiencies using ICT, staff must actively engage with the wider Greening Government Commitments and be challenged to address sustainability in their day-to-day activities.

\section{E-agriculture}

UK government published "A UK Strategy for Agricultural Technologies" policy paper in 2013 and annually updates it.

Britain claims that it is pioneer of industrial and also agricultural revolution. Since agricultural science and technology is rapidly growing, UK tries to be a leader in this field. UK commitments are as fallow [66]:

- We have institutes and university departments at the forefront of areas of research vital to agriculture and related technologies.

- We have innovative and dynamic farmers, food manufacturers and retailers.

- We are well positioned to make an impact on global markets through exports of products, science and farming practices.

Regards to these commitments, UK plans strategies and design projects to reach them.

- Improve the translation of research into practice through a $£ 70$ million Government investment in an Agri-Tech Catalyst which will provide a single fund for projects, all the way from the laboratory to market. This will include $£ 10$ million to deliver international development objectives

- Increase support to develop, adopt and exploit new technologies and processes through $£ 90$ million of Government funding for Centers for Agricultural Innovation

- Help the UK exploit the potential of big data and informatics and become a global center of excellence by establishing a Centre for Agricultural Informatics and Metrics of Sustainability

- Provide stronger leadership for the sector. The Leadership Council gives industry a stronger and more cohesive voice with Government and the science base

- Build a stronger skills base through industry-led actions to attract and retain a workforce who are expert in developing and applying technologies from the laboratory to the farm

- Increase alignment of industry research funding with public sector spend by increasing understanding of what is being spent and where

- Increase UK export and inward investment performance through targeted sector support

\section{E-science}

The term 'e-Science' was introduced by Dr. John Taylor, Director General of Research Councils in the UK Office of Science and Technology (OST) [67]. 
Page 10 of 15

Generally, e-Science has focused on the development of new computational tools and infrastructures to support scientific discovery.

UK has the important e-science program that was the pioneer in that period. In November 2000 Dr. John Taylor allocated $£ 98$ million for a national UK e-Science program. Science Minister David Sainsbury and the Chancellor of the Exchequer Gordon Brown supported his project fully. Also UK industry contributed $£ 20$ million to the project. From this budget of $£ 120$ million over three years, $£ 75$ million was to be spent in all areas of science, administered by the Research Council responsible for each area, while $£ 35$ million was to be administered by the Engineering and Physical Sciences Research Council (EPSRC) as a Core Program to develop "industrial strength" Grid middleware. Phase 2 of the program for 2004-2006 was supported by a further $£ 96$ million for application projects, and $£ 27$ million for the EPSRC core program. Phase 3 of the program for 2007-2009 was supported by a further $£ 14$ million for the EPSRC core program and a further sum for applications [68].

There are 11 pilot e-Science projects by EPSRC as follows [69]:

- The Reality Grid; a tool for investigating condensed matter and materials.

- Comb-e-chem - Structure-Property Mapping: Combinatorial Chemistry and the Grid.

- Distributed Aircraft Maintenance Environment: DAME.

- Grid Enabled Optimization and Design Search for Engineering (GEODISE).

- Discovery Net: An e-Science Testbed for High Throughput Informatics.

- My Grid: Directly Supporting the e-Scientist.

- GOLD: practical aspects of developing and deploying virtual organizations (VOs) and develop proof-of-concept middleware and tools to demonstrate VOs in an industrial chemical engineering context.

- Integrative biology: understanding of the causes of cancer and cardiovascular disease through a combination of mathematical and computational modeling; on the technology side, it is building the underlying Grid infrastructure required to support this research.

- PMSEG (Message).

- CARMEN: understanding of the way in which information is encoded, accessed, analyzed, archived and decoded in neuronal networks.

- Nano CMOS: minimization of metal-oxide-semiconductor (CMOS) transistors to make cheaper and faster devices.

\section{C8-Cultural diversity and identity, linguistic diversity and local content}

Multiculturalism is one of British society features.so it is necessary the government concerns about cultural diversity, identity and linguistic diversity.

According to the 2011 census, the total population of the United Kingdom was around 63,182,000 [70]. Related part of this report is Ethnic Groups in UK. Studying this part shows that there are diversity cultures in UK (Table 1).

About 8 millions of British citizens are originally from another country. Also some of them are have British identity and citizenship but it is obvious that they have some unique and different customs ad values.

\begin{tabular}{|l|l|l|}
\hline Ethnic group & $\begin{array}{l}\text { Population } \\
\mathbf{( 2 0 1 1 )}\end{array}$ & $\begin{array}{l}\text { Percentage of total } \\
\text { population }\end{array}$ \\
\hline White: Total & $55,010,359$ & 87.1 \\
\hline $\begin{array}{l}\text { Gypsy/Traveler/ Irish Traveler: } \\
\text { Total }\end{array}$ & 63,193 & 0.1 \\
\hline Asian or Asian British: Indian & $1,451,862$ & 2.3 \\
\hline Asian or Asian British: Pakistani & $1,174,983$ & 1.9 \\
\hline $\begin{array}{l}\text { Asian or Asian } \\
\text { Bangladeshi }\end{array}$ & 451,529 & 0.7 \\
\hline Asian or Asian British: Chinese & 433,150 & 0.7 \\
\hline $\begin{array}{l}\text { Asian or Asian British: Other } \\
\text { Asian }\end{array}$ & 861,815 & 1.4 \\
\hline Asian or Asian British: Total & $4,373,339$ & 6.9 \\
\hline Black or Black British: Total & $1,904,684$ & 3 \\
\hline Mixed or Multiple: Total & $1,250,229$ & 2 \\
\hline Other Ethnic Group: Total & 580,374 & 0.9 \\
\hline Total & $63,182,178$ & 100 \\
\hline
\end{tabular}

Table 1: 2011 Census, the total population of the United Kingdom.

In 2006, Gordon Brown, then Chancellor of the Exchequer, made a speech about promotes Britishness. He talked about the necessity of a new constitutional settlement and symbols to represent a modern patriotism, including a new youth community service scheme and a 'British Day' to celebrate [71,72].

A survey conducted in 2007 found that the majority of people in many non-white ethnic groups living in Great Britain described their national identity as British [73].

Because United Kingdom is including England, Wales, Scotland and Northern Ireland, she should care about protect this unity. So the national color of UK and its flag is white, blue and red. It represents the old flag of those independent countries that are united now (Figure 1).

In1976 the Commission for Racial Equality (CRE) as a nondepartmental public body in the United Kingdom founded. It aimed to address racial discrimination and promote racial equality. It was established by the Race Relations Act 1976, under James Callaghan's Labor government.

The Race Relations Act 1976 was established by the Parliament of the United Kingdom to prevent discrimination on the grounds of race, color, nationality and religion. It covered non-discrimination in fields of employment, the provision of goods and services, education and public functions.

The Identity Cards Act 2006 was another Act of the Parliament of the United Kingdom about Britishness. It created national identity cards, a personal identification document and European Union travel document.

\section{C9- Media}

The Communications Act of 2003 made Ofcom the independent regulator for both the telecommunications and broadcasting industries in the UK, responding to the growing convergence of those industries. 
Ofcom currently regulates broadcasting, including public service television broadcasters (BBC, Channel 4, S4C, ITV and Five), as well as telecommunications and the post. The Secretary of State for Culture, Media and Sport appoints the Chair of Ofcom [74,75].

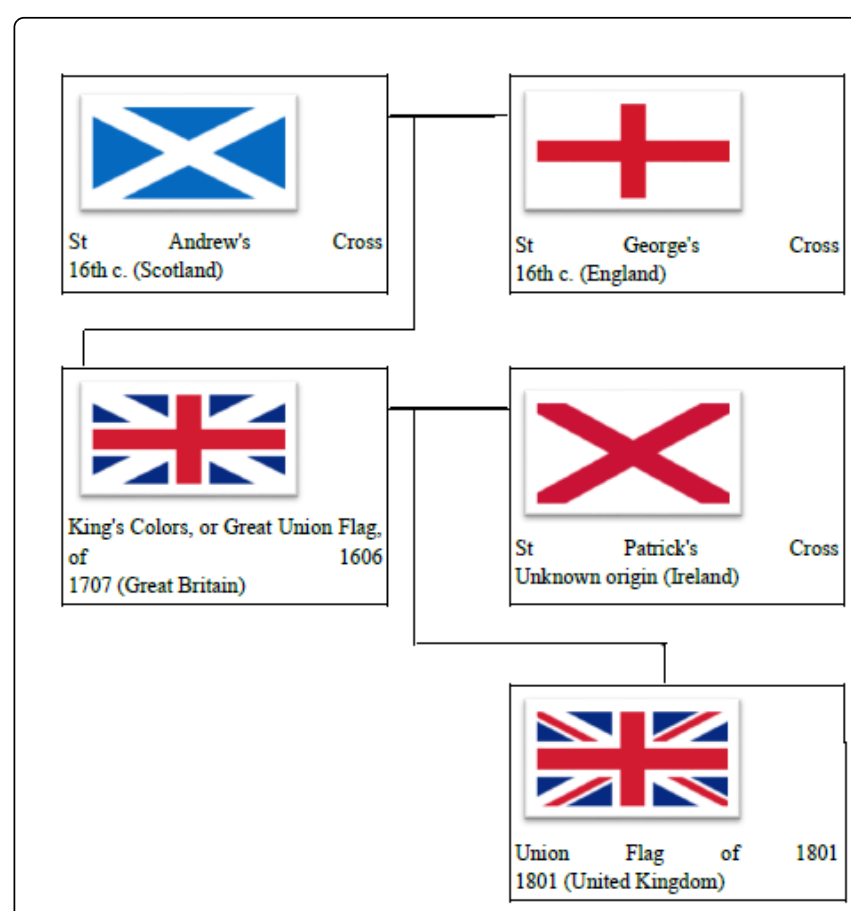

Figure 1: Old flag of the independent countries that are united now.

UK claims that her media and telecommunications sectors reflect all aspects of modern British life, and provide a platform to showcase Britain to the world so in the past two years they reviewed the legislative framework governing the media and telecommunications sectors to ensure that it remains appropriate for the digital age.

In the 2013 Budget, UK government distribute a $£ 15$ million competition to be run by the Technology Strategy Board, inviting bids to support digital content production through partnership with industry, including specialist SMEs, educational research facilities and training providers [76].

\section{C10- Ethical dimensions of the information society}

According to $\mathrm{C} 10$, ethical dimensions of the information society includes [1]:

- Equality of access.

- Freedom of expression: a right with responsibilities.

- Identity and social networks.

- Security and governance.

UK government in 2015 claims that it plans to make sure no-one is left behind on broadband access [77].

The Prime Minister David Cameron said, "Access to the Internet shouldn't be a luxury; it should be a right - absolutely fundamental to life in 21 st century Britain. That is why I'm announcing a giant leap in my digital mission for Britain. Just as our forebears effectively brought gas, electricity and water to all, we're going to bring fast broadband to every home and business that wants it" [78]. It will be done through a Universal Service Obligation (USO).

About freedom of expression and censorship, in 1998, the United Kingdom incorporated the European Convention, and the guarantee of freedom of expression it contains in Article 10, into its domestic law under the Human Rights Act.

\section{Article 10 (Freedom of thought, conscience and religion) said that:}

- Everyone has the right to freedom of thought, conscience and religion. This right includes freedom to change religion or belief and freedom, either alone or in community with others and in public or in private, to manifest religion or belief, in worship, teaching, practice and observance [2].

- The right to conscientious objection is recognized, in accordance with the national laws governing the exercise of this right [79].

\section{C11- International and regional cooperation}

There are regional and international agreements between UK and other countries to ease ICT trade, guarantee the security and safety in the cyber space, e-commerce, provide suitable information and communication infrastructure. The researcher will mention some of those bilateral agreements.

UK allocated billions Euro to enhancing access to, and use and quality of, ICT in the European Regional Development Fund (ERDF) and the European Agricultural Fund for Rural Development (EAFRD) in 2014. UK allocated $€ 241,812,709$ to ERDF and $€ 25,065,356$ to (EAFRD) total $€ 266,878,698$. This budget amid improving ICT infrastructure in order to address clear market failures and bring forward planned initiatives to improve local growth at a faster rate and with greater benefit and increase ICT take up by businesses [80].

In 2013, UK and Japan signed a bilateral memorandum on the security of information. This agreement provides a legal basis for the protection of classified information exchanged between the countries, including in areas such as defence, law enforcement, counterterrorism and security [81].

In 2010, United Kingdom and United States of America signed an agreement for the sharing of visa immigration and nationality information. This agreement is very important to provide more safety in both countries [82].

In January 2015, UK and Spain signed a bilateral agreement about protection of classified information [83].

In September 2015, UK and Luxemburg signed an agreement about concerning the protection and promotion of classified information [84].

In December 2004, UK and United states signed a bilateral agreement in London on Cooperation in Science and Technology for Critical Infrastructure Protection and other Homeland/Civil Security Matters [85].

In May 2006, UK and the Russian Federation exchanged notes of amending the Agreement on Science and Technology Cooperation, done at Moscow on 28 May 1996 [86].

In June 2012, a bilateral agreement between the Government of the United Kingdom of Great Britain and Northern Ireland and the Government of the Republic of Finland signed a deal about concerning the Mutual Protection of Classified Information [87]. 
Page 12 of 15

UK signed alike agreement with Bulgaria. United Nations presented Convention on the Use of Electronic Communications in International Contracts in 2008 and UK was one the country that signed it.

\section{Information Society: Agenda for Action in the UK}

Agenda for action in the UK is the first Select Committee report from either House of the United Kingdom Parliament is about one of the most important technological developments of this century means digital and communications revolution. This enquiry began in 1996 and lasted for 5 months.

The report has 6 chapters. Chapter 1 discusses the technology behind the development of the information superhighways, and the infrastructure in the United Kingdom. Chapter 2 discusses national information infrastructure policies. Chapter 3 discusses some of the approaches which other countries, and the European Union, are adopting to the Information Superhighways, with a view to seeing what lessons the United Kingdom can learn from these international perspectives. It also outlines current parliamentary developments, including those in the House of Lords. Chapter 4 discusses the views of witnesses. Chapter 5 discusses the Opinion of the Committee and its key recommendations. But the most important chapter is chapter 6 that is outlines a 40-point agenda for action in the UK. Our recommendations include the setting up of an Information Society Task Force in the UK, similar to that which has operated successfully in the US [88].

It emphasizes on necessity of fundamental changes to the regulatory framework and specific actions to be taken by Government, including the promotion of electronic publishing to facilitate widespread access to Government publications.

Also it recommended on the subjects of universal access; education; health care; environmental benefits; electronic publishing and archiving; encryption and verification; and grants [89].

\section{Digital Britain}

The Digital Britain report was a policy document published in 2009, which outlined the United Kingdom Government's strategic vision for ensuring that the country is at the leading edge of the global digital economy.

It is about being digital, a competitive digital communication infrastructure, radio: going digital, creative industries in the digital world, public service content in the digital Britain, research, education and skills for digital Britain, digital security and safety, the journey to digital government and delivering digital Britain [90].

This report recommended 22 actions that some important ones are:

- Three-year plan to boost digital participation.

- Universal access to broadband by 2012.

- Fund to invest in next generation broadband.

- Digital radio upgrade by 2015.

- Liberalization of $3 \mathrm{G}$ spectrum.

- Support for public service content partnerships.

- Changed role for Channel 4.

- Consultation on how to fund local, national and regional news.

- A new "more robust system" for the classification of video games.

\section{Conclusion}

After analyzing findings, the researcher answers questions.

What measures were taken by United Kingdom in WSIS (World Summit on Information Society)?

The researcher discussed fully about UK measures in WSIS. According to UK delegations' speeches at WSIS meetings, UK emphasized on closer cooperation between governments and nongovernmental stakeholders. Also, it cared about freedom of speech and protects fundamental rights of journalist according to action line. UK believed in equal right of access to information and cyber space.

Besides, UK has emphasized make an explicit link between WSIS and the 2030 Sustainable Development Agenda.

The country called all governments to ease investment regulation, especially in ICT sectors to improve this sector and achieve to WSIS goals.

John Whittingdale, UK Secretary of State for Culture, Media and Sport at the UN General Assembly High-Level Meeting on the World Summit of the Information Society (WSIS) said:' The UK has played a leading role in the evolution of ICTs - from the early development of telegraphy and the first submarine cables, to the work of the Marconi Company in radio-communications in my own area of Chelmsford. And that pioneering work continues, from the invention of the World Wide Web by Sir Tim Berners-Lee, right up to the development of $5 \mathrm{G}$ mobile" [91].

In the speech, The UK called on all countries to protect and promote human rights and fundamental freedoms.

In which categories of information society has United Kingdom been most active in WSIS?

Regards to workshops, exhibitions and speeches done by UK delegation, the researcher can categorize the main priorities of UK in the WSIS. UK has been most active in the fallowing parts:

- The role of governments and all stakeholders in the promotion of ICTs for development (C1)

- Information and communication infrastructure: an essential foundation for an inclusive information society (C2)

- Human right (C3, C9, C10)

What are the future priorities of the UK in the field of information society?

The researcher fully discussed about UK priorities. Here there is summary of that and categorizing the priorities:

UK government as a member of EU through Horizon 2020 grant fund researcher and scientist to reach information society agendas as follows [92]:

- Involve ground breaking research or new technologies

- Improve research training and development, or research infrastructure

- Create growth in sectors like advanced manufacturing, materials, biotechnology, information and communication technology, nanotechnology and space

- Increase private investment in research

- Respond to challenges like climate change, food security or healthcare for an ageing population 
It shows UK persistence and also commitment to reach WSIS action lines and its aims.

UK supports new technologies and its related researches and developments [93].

To guarantee cyber and consumer protection is another priority of UK plans for the future [93].

Mark Matthews, ambassador and deputy permanent representative to the United Nations and other International Organizations in Geneva as ITU made a speech in the meeting WSIS High-Level Event 2014 [94-100].

He said that: "For us, the principles of freedom of expression, the independence, plurality and diversity of the media and the safety of journalists are fundamental, any text which does not include those principles cannot be said to be balanced" [26].

According to these and some other documents, the researcher can categorize UK priorities as follows [101-112]:

- Equality between genders and races.

- Respect to freedom of expression especially for journalists.

- Special attention to the role of the economic dimensions of culture.

- The balance between elites and the rest, the access to the urban 'commons'.

- The balance between public and private cultural values, notably the emphasis of commercial values and consumption.

- To develop digital infrastructure.

- To develop Green Infrastructure.

- To develop online education, course (for example improves "Open University).

- To develop UK Green Investment Bank.

- To guarantee cyber and consumer protection.

- To provide more digital jobs.

- To remove or at least diminish barriers for women and ethnic minority to access equal right to information, education and take STEM career.

- To train digitally skilled worker for digital jobs.

- To use computer vision.

- To use energy harvesting.

- To use fiber optics.

- To use low power sensors based on micro electro mechanical systems (MEMS).

- To use wireless sensor networks.

- UK supports new technologies.

\section{References}

1. Report of the Tunis phase of the WSIS (2006) International Telecommunication Union.

2. International Telecommunication Union (2003) Declaration of principles-Building the information society: A global challenge in the new millennium. World Summit on the Information Society.

3. Haddon L (2004) Information and communication technologies in everyday life. Berg Publishers, Oxford.

4. Martin WJ (1995) The global information society. Aslib, London.

5. Adetunji J, Awojobi E, Adeleke T, Appah Helen D, Benedicta OE, et al. (2014) Information society in Nigeria: the role of government and private sector. Arabian J Bus Manag Review 3: 85-100.
6. Gudauskas R (2012) National information policy, information infrastructure and libraries. World Library and Information Congress, Helsinki.

7. United Nation General Assembly (2002) World Summit on the Information Society. International Telecommunication Union.

8. United Nation General Assembly (2015) Outcome document of the highlevel meeting of the General Assembly on the overall review of the implementation of the outcomes of the World Summit on the Information Society. UNPAN.

9. World Summit (2003) Plan of action. International Telecommunication Union(ITU).

10. World Summit (2005) Tunis agenda for the information society. International Telecommunication Union (ITU).

11. World Summit (2015) General assembly high-level meeting -15-16 December 2015. United Nations.

12. World Summit (2015) Implementing WSIS outcomes. UNCTAD.

13. Aniogbolu U, Ejitagha (2015) Implementation of the ideas of world summit. Research in education and society.

14. UNESCO (2012) UIS database, partnership on measuring ICT for development WSIS targets. UNESCO Institute for Statics (UIS).

15. Mansell R (2009) Telecommunications in the UK: controlling the information society gateways. LSE Research Online.

16. Government of UK (2004) Commission communication: Annual policy strategy for 2005. Committee on European scrutiny, UK.

17. Kaspar L (2015) The road to WSIS+10: Key country perspectives in the ten-year review. Global Partners Digital.

18. World Summit (2003) Final list of participants, Geneva. International Telecommunication Union (ITU).

19. Stephen T (2003) Speech by Stephen Timms, United Kingdom minister of energy, e-commerce and postal services. International Telecommunication Union (ITU).

20. World Summit (2005) Final list of participants, Tunsia. International Telecommunication Union (ITU).

21. World Summit (2005) Statement from United Kingdom, Alun Michael, minister of state for industry and regions. International Telecommunication Union (ITU).

22. World Summit (2005) WSIS phase II - civil society orientation kit. The United Nations Non-Governmental Liaison Service (UN-NGLS).

23. World Summit (2013) WSIS forum 2013 outcome document International Telecommunication Union (ITU).

24. World Summit (2015) WSIS 2015: policy statement. International Telecommunication Union (ITU).

25. World Summit (2013) WSIS+10 visioning challenge: WSIS beyond 2015. International Telecommunication Union (ITU).

26. World Summit (2014) WSIS high-level event 2014 policy statements. International Telecommunication Union (ITU).

27. World Summit (2015) WSIS Forum 2015: policy statements. International Telecommunication Union (ITU).

28. UNPAN (2015) UK contribution to EU opening statement. United Nations Public Administration Network.

29. World Summit (2005) Golden book: Stakeholder commitments and initiatives. International Telecommunication Union (ITU).

30. World Summit (2004) How governments treated civil society proposals in drafting the 19 September 2003 draft plan of action. International Telecommunication Union (ITU).

31. Cabinet Office (2011) UK government ICT strategy. UK Government.

32. Department for International Trade (2014) Information Communications Technology (ICT) in the UK: Investment opportunities. GOV.UK.

33. (2014) UK software market returning to growth, driven by cloud computing. Tech Market View.

34. Cabinet Office (2014) Cyber security strategy. GOV.UK.

35. HM Treasury (2015) Policy paper: The digital communications infrastructure strategy. UK Government. 
Page 14 of 15

36. http://media.ofcom.org.uk/news/2014/icmr-2014/

37. World Summit (2014) Final WSIS targets review. International Telecommunication Union (ITU).

38. http://www.connectionvouchers.co.uk/

39. https://www.supremecourt.uk/about/access-to-information.html

40. World Summit (2015) WSIS prizes 2015. International Telecommunication Union (ITU).

41. National University of Singapore (2013) Is Accessing the internet is a human right.

42. Murray A, Klang M (2005) Human rights in the digital age. RoutledgeCavendish, London.

43. Department for Culture Media and Sport (2015) The digital communications infrastructure strategy. GOV.UK.

44. European Commission (2015) Summary of broadband development in the United Kingdom. Digital Agenda for Europe.

45. Digital Agenda for Europe (2014) Britain's superfast broadband future. European Commission.

46. Government of UK (2015) Further education and skills. GOV.UK.

47. (2015) Skills policy in the UK. CIPD:Chartered Institute of Personnel and Development.

48. Government of UK (2014) UKCES futures programme: an introduction. GOV.UK.

49. Cyber Security (2015) UK cyber security a top priority for UK Government. GOV.UK.

50. World Summit (2015) WSIS stocktaking. International Telecommunication Union (ITU)

51. International Telecommunication Union (2015) C7. ICT applications: benefits in all aspects of life. WSIS Stocktaking.

52. European Commission (2014) e-government in the UK. European Union.

53. Government of UK (2014) Beyond e-commerce to everywherecommerce. GOV.UK.

54. Garson GD, Khosrow-Pour M (2008) Handbook of research on public information technology. Information Science Reference, Newyork.

55. Kuchler H (2016) UK 'leads the world' in e-commerce. Financial Times.

56. Laurillard D (2005) Transforming learning and children's services. Department for Education and Skills, GOV.UK, London.

57. Department for Education and Skills (2003) Towards a unified e-learning strategy: consultation document.

58. Hammersley M (2002) Educational research, policymaking and practice. Sage Publications, London.

59. Higher Education Network (2014) Online learning: the UK's scepticism is holding it back. The Gaurdian.

60. Government of UK (2014) e-Health in the United Kingdom. e-service.

61. Dixon T, Thompson B, McAllister P, Marston A, Snow J (2005) Real estate and the new economy: The impact of information and communications technology. Wiley-Blackwell, Hoboken.

62. Cabinet Office (2013) Greening government ICT strategy. Gov.UK, London.

63. Boss J (2015) Greening government ICT 2014 Annual Report. Gov.UK London.

64. Boss J (2015) Greening Government ICT 2014 Annual Report. Gov.UK London.

65. HM Government (2011) Greening Government: ICT Strategy. GOV.UK, London.

66. HM Government (2013) A UK strategy for agricultural technologies.

67. Bohle S (2013) What is E-science and how should it be managed. Scilogs.

68. http://www.nesc.ac.uk/

69. Hey T, Trefethen AE (2002) The UK e-science core programme and the grid. Future Gener Comp Sy 18: 1017-1031.

70. National Statistics (2012) 2011 Census: population estimates for the United Kingdom. Office for National Statistics.

71. BBC (2006) Brown speech promotes Britishness. BBC News.
72. Fabian Society (2006) The future of Britishness.

73. (2009) Social Trends. Office for National Statistics, London.

74. http://www.ofcom.org.uk/

75. Government of UK (2003) Communication act 2003. Legislation.GOV.UK.

76. HM Treasury (2013) Budget 2013. GOV.UK, London.

77. Department of Culture (2015) Government plans to make sure no-one is left behind on broadband access. GOV.UK, London.

78. The Guardian (2015) Cameron vows to make fast broadband available to every home in UK.

79. European Parliament (2000) Charter of fundamental rights of the European Union. Official Journal of the European Communities 364:1-22.

80. European Commission (2014) Summary of the partnership agreement for United Kingdom.

81. Governemt of UK (2014) UK/Japan-agreement on the security of information.

82. https://www.gov.uk/government/uploads/system/uploads/ attachment_data/file/226265/No_16_CM_8651_USA.pdf

83. Government of UK (2015) Agreement between the United Kingdom and the kingdom of Spain: Protection of classified information. UK Treaties Online, London.

84. Government of UK (2015) Agreement between the United Kingdom and the grand duchy of luxembourg: Protection and promotion of classified information. UK Treaties Online, London.

85. UK treaties (2004) UK and US: On cooperation in science and technology for critical infrastructure protection and other homeland/civil security matters.

86. UK treaties (2006) UK and Russia: science and technology cooperation.

87. UK Treaties (2012) UK, Finland/mutual protection of classified information.

88. UK Parliament (1996) Agenda for action in the UK. Parliament, UK.

89. Government of UK (1996) Chapter 6: The agenda for action in the UK. Paliament, UK.

90. Department for Business Innovation and Skills (2009) Digital Britain. GOV.UK, London.

91. John W (2015) Statement by John Whittingdale, UK secretary of state for culture, media and sport. GOV.UK, London.

92. https://www.gov.uk/horizon-2020

93. Department for Business Innovation and Skills (2015) Digital priorities for this Parliament. GOV.UK, London.

94. APC (2005) WSIS: APC makes recommendations on internet governance at UN summit.

95. World Summit (2005) Basic Information: About WSIS. International Telecommunication Union (ITU).

96. European Commission (2015) Digital economy and society index. Digital Single Market.

97. Association for Progressive Communications (2014) GlossaryAssociation for progressive communications. Association for Progressive Communications.

98. ITU (2015) ICT Development Index-2015.

99. http://projects.oucs.ox.ac.uk/vre/ibvre/index.xml?splitLevel=-1

100. Karvalics LZ (2007) Information society - what is it exactly? Budapest University of technology and economics: The information society and trend research institute. European Commission: Information Society.

101. Karvalics LZ (2007) Information Society - what is it exactly. European Commission, Budapest.

102. Karvalics LZ (2009) Information society dimensions. Szeged, Jate Press, Hungary.

103. McPhail TL (2009) Development communication: Reframing the role of the media. Wiley-Blackwell, Hoboken. 
Citation: Abedini E (2016) The Global Trends of WSIS: A Case Study of UK's Plans and Measures on Information Society. Arts Social Sci J 7: 217. doi:10.4172/2151-6200.1000217

Page 15 of 15

104. Mueller ML (2010) Networks and states: The global politics of internet governance. The MIT Press, Cambridge.

105. Muranyi B (1995) National Strategy for Information Society in Hungary.

106. Oxford (2014) Oxford Dictionary. Oxford University Press.

107. Government of UK (1976) Race Relations Act 1976. Legislation.GOV.UK, London.

108. Perlo-Freeman S, Solmirano C (2014) Trends in world military expenditure, 2013.
109. Acharya S (2015) UK ranks fourth in the world for IT and telecommunications access. International Business Times.

110. World Economic (2015) World Economic Outlook. International Monetary Fund.

111. https://en.wikipedia.org/wiki/ world_summit_on_the_information_society

112. World Summit (2003) WSIS reference document. International Telecommunication Union (ITU). 